\title{
Entre o movimento estudantil e a luta armada: Eudaldo Gomes da Silva e o "Massacre da Chácara São Bento" (1960/1970)
}

\author{
Lucileide Costa Cardoso*
}

Entre silêncios, esquecimentos e lembranças pretendemos contar a história de Eudaldo Gomes da Silva a partir de cinco entrevistas, realizadas com engenheiros agrônomos de formação, seus contemporâneos de luta estudantil em Cruz das Almas, cidade do Recôncavo Baiano. Investigamos também a documentação produzida pela Escola Agronômica da Bahia (EAB), livros de atas, e uma série de documentos produzidos pelo Diretório Acadêmico Landulfo Alves (Dala), com o objetivo de melhor compreender o contexto político vivido por eles, permitindo o surgimento de novas lideranças no cenário baiano.

Ao discutir os embates vividos dentro e fora da escola, demonstraremos quais foram os caminhos seguidos por alguns desses jovens que passaram do engajamento no movimento estudantil para a luta armada. Nesse ponto, as entrevistas serão analisadas não somente para que a cartografia da vida do nosso personagem seja desenhada, mas para recuperar identidades perdidas no tempo, envolvendo a dimensão estudantil e a opção pela guerrilha. Sobre o período de engajamento de Eudaldo na luta armada, após 1969, analisaremos fontes jornalísticas e a documentação do Departamento de Ordem Política e

* Professora de História Contemporânea do Departamento e Programa de Pós-Graduação em História da Universidade Federal da Bahia (UFBA). Líder do grupo de pesquisa Cultura, Memória e Política Contemporânea (UFRB/UFBA/UFS). Integrante do projeto de pesquisa "Estado e memória: políticas públicas da memória da ditadura portuguesa (1974-2009)”, Universidade do Porto/Fundação para a Ciência e Tecnologia em Portugal (PTDC/HIS-HIS/121001/2010). 
Social (Dops) que informam sobre a sua militância no Rio de Janeiro, prisão, tortura, exílio e o episódio noticiado pela imprensa como o "Massacre da Chácara São Bento", ocorrido em Pernambuco em 1973.

Algumas inquietações orientaram a pesquisa que procurou retirar do anonimato uma história esquecida na própria $\mathrm{EAB}$ e na região do Recôncavo Baiano. Como entender a sua passagem de militante estudantil para guerrilheiro? Quais foram os elementos formadores de uma consciência política que influenciou uma geração de jovens, estudantes da Escola Agronômica da Bahia, entre os anos 1960 e 1970? Como repercutiu os posicionamentos e ações do movimento estudantil no plano nacional no interior dessa escola, determinando a formação de novas lideranças? Por que tais lideranças, surgidas nesse contexto, ainda não foram reconhecidas pela historiografia sobre o movimento estudantil e pela própria União Nacional dos Estudantes (UNE)? Mais que isso, o que leva um jovem a desistir de receber o seu diploma de engenheiro agrônomo, recusando-se a participar da formatura junto com os colegas, partindo para "fazer a revolução"? Quais as motivações de uma geração que sonhou com a revolução, mas logo acordou com a repressão? Enfim, qual a memória que sobrevive de Eudaldo Gomes da Silva na Bahia? Memória heroica, desconhecimento, apagamento?

Seguindo o curso dessas questões, recuperamos alguns traços de sua biografia para situar o personagem, fonte e objeto de reflexão nessa pesquisa. Eudaldo (1947-1973) nasceu em Salvador, Bahia, filho de João Gomes da Silva e de Isaura Gomes da Silva. Seu pai, como carpinteiro do Colégio Dois de Julho, conseguiu para o filho uma bolsa de estudo. Eudaldo concluiu o seu curso secundário nesse colégio particular de classe média soteropolitana, ingressando na EAB, localizada em Cruz das Almas, em 1966. Durante o curso, em 1968, tornou-se presidente do Dala e membro do Diretório Central dos Estudantes (DCE) da Universidade da Bahia. Em finais de 1969, abandona o curso de Agronomia, passando a viver na clandestinidade, condição de sobrevida dos que optaram pela luta armada contra a ditadura. Em junho de 1970, foi preso no Largo da Glória, no Rio de Janeiro, quando executava tarefas de levantamento para a ação de sequestro do Embaixador da República Federal Alemã para fins de negociação e troca de presos políticos ameaçados de tortura e morte. Eudaldo resistiu às duras sessões de tortura; os agentes do Destacamento de Operações de Informações - Centro de Operações de Defesa Interna (DOI-Codi) não conseguiram extrair nada dele, o que permitiu que o plano do sequestro fosse bem sucedido. 
Incluído na relação dos que seriam trocados pela pessoa do embaixador, Eudaldo foi "banido" do Brasil em 15 de julho de 1970. Seguiu para Argélia com mais 39 presos políticos, entre eles Fernando Gabeira, Vera Sylvia Magalhães, Daniel Aarão Reis Filho, entre outros. Depois foi para Cuba, onde fez treinamento para a guerrilha e, de lá, rumo ao Chile, na época vivendo a experiência democrática e socialista do governo de Salvador Allende. No exílio sempre manifestou o desejo de retornar ao Brasil e continuar a resistência interna. Assim, regressou com o objetivo de rearticular as bases para preparar um congresso e definir novas formas de luta e reorganização da Vanguarda Popular Revolucionária (VPR). Não demorou muito, ele e seus companheiros foram traídos pelo ex-cabo Anselmo. Preso com vida na Chácara São Bento, no município de Paulista, em Pernambuco, pelo DOI-Codi local, com o apoio do delegado Sérgio Paranhos Fleury, do Dops paulista, Eudaldo morreu sob tortura.

A versão oficial distribuída à imprensa pelo Serviço de Relações Públicas do IV Exército em Recife é de que foi morto no dia 7 de janeiro de 1973, juntamente com Evaldo Luiz Ferreira de Souza, Soledad Barret Viedma, Pauline Reichstul, José Manuel da Silva e Jarbas Pereira Marques. O caso ficou conhecido como "Massacre da Chácara São Bento", manchete de vários jornais, divulgando a falsa versão de que ao resistirem à prisão foram mortos em tiroteio na própria chácara.

\section{Movimento estudantil em Cruz das Almas}

A antiga Escola Agronômica da Bahia origina-se da criação do ensino agrícola no Brasil em 1877 com a fundação da Imperial Escola Agrícola. Em 1944, Cruz das Almas passou a sediar a escola mantida pelo Estado até meados dos anos 1960 quando passou a ser federalizada (Baiardi, 2000). A EAB foi palco de intensa movimentação política no pré e pós-golpe de 1964. O estudante Amilcar Baiardi presidiu o Dala, entre os anos de 1962 a 1964, juntamente com José Alberto Bandeira Ramos, Luiz Fernando Velloso, entre outros. A convivência com a direção da escola nem sempre foi pacífica, revelando impasses e fortes divergências políticas. Muitos desses estudantes já atuavam no Partido Comunista Brasileiro (PCB), como era o caso de José Alberto Bandeira Ramos, historiador, membro da Frente Nacionalista de Cruz das Almas nos anos 1960 e professor da EAB nas décadas seguintes. 
A inflexão política de 1964 permitiu que o campus fosse invadido, estudantes e professores perseguidos, ocorrendo prisões de trabalhadores do campo da EAB. Contudo, nem todos foram vítimas do regime, atitudes colaboracionistas vieram à tona. Membros da direção da escola posicionaram-se a favor das medidas tomadas pelo "Comando Supremo da Revolução", especialmente a edição do AI-1 que estabelecia punições aos membros do governo Jango e demais suspeitos. Durante uma reunião da congregação, os professores e demais representaçôes, aprovaram o envio de um telegrama ao general presidente Castelo Branco parabenizando-o pelo estabelecimento de uma nova ordem regida pela democracia contra o comunismo. Os termos destacados na Ata de 13 de Abril de 1964/Congregação da E.A.B. evidenciam as atitudes da direção da escola de apoio incondicional ao regime civil-militar:

O senhor presidente José de Vasconcelos Sampaio [...] declarou que no intervalo compreendido entre a reunião passada e o presente houve uma revolução nacional, em que as classes armadas visaram reintegrar o país na órbita democrática e na linha da evolução cristã. Teceram entusiásticos elogios as classes armadas pelo seu alto espírito democrático e pelo modo decisivo e patriótico com que procuraram eliminar o comunismo ateu do organismo pátrio. Disse que a diretoria da Escola se manteve serena e vigilante, em contexto com as autoridades, com docentes e discentes e em consonância com as medidas tomadas pelo Comando Revolucionário, para solver a guarda do regime democrático brasileiro, tendo baixado portarias destituindo a direção do Diretório Acadêmico Landulfo Alves e dissolvendo a Associação Beneficente dos Trabalhadores da E.A.B. por suspeição de infiltração comunista no seu seio, lendo cópias das citadas portarias. [...] Por proposta do professor Gilberto da Mota, a congregação, por unanimidade, resolveu fosse passado um telegrama de apoio e congratulações ao Presidente da República, eleito, General Castelo Branco. [...] O professor Geraldo Pinto disse do compromisso patriótico que se deve assumir com a pátria ameaçada pelo comunismo e a necessidade de se passar da fase do aplauso à colaboração com as Forças Armadas, no sentido de descomunização do pais. (Grifo nosso).

No confronto com a implantação das novas políticas educacionais por parte da direção da escola, especialmente o acordo MEC-USAID, vários professores e estudantes manifestaram atitudes de resistências contrárias aos 
golpistas e na defesa do ensino público com autonomia. Indícios de alianças entre o movimento universitário da EAB e o movimento secundarista do Colégio Alberto Torres, espécie de colégio-modelo da cidade, aparecem nos depoimentos orais, demonstrando a inserção da $\mathrm{EAB}$ no quadro mais amplo de atuação na comunidade cruzalmansense.

Os registros encontrados possibilitam compreender a história do movimento estudantil na EAB a partir de três momentos significativos. O primeiro, marcado pela influência da Frente Nacionalista em Cruz das Almas, atuando como lideranças entre os anos de 1962 e 1964, José Alberto Bandeira Ramos, presidente do diretório acadêmico em 1962, Cyro Mascarenhas Rodrigues e Amilcar Baiardi. Este último, presidente do Dala em 1964, tentou organizar uma resistência armada logo após a notícia do golpe, mas tal empreitada se revelou impossível e foi frustrada. Esse período foi marcado também por uma luta para manter no interior da escola a autonomia do diretório frente às diversas tentativas de controle por parte da direção.

A segunda fase compreende o pós-64 até 1969, com a geração participante e dirigente do Dala, formado pelos estudantes Eudaldo Gomes da Silva, Igor Coelho, Abdon Jordão Filho, Armando Rosa, Joelito, entre outros. Nesse período, greves e diversas mobilizaçóes para manter a qualidade do ensino agronômico na Bahia se fizeram sentir. Após a edição do AI-5, em 13 de dezembro de 1969, presenciamos um refluxo no movimento estudantil no Recôncavo, fenômeno também presente em várias partes do Brasil, principalmente pela escalada da repressão, culminando com prisões, assassinatos e exílios.

A terceira fase se caracteriza por uma necessidade de reorganização do movimento estudantil no plano nacional, fazendo ressurgir na EAB as lutas estudantis por volta de 1977, naturalmente dentro de um contexto de luta pela anistia política. A Campanha pela Anistia alcançou na Bahia um papel de destaque com a realização do II Congresso Nacional de Anistia, em 1979, em Salvador. Nos poucos documentos restantes do Dala nessa fase, encontramos menção ao grupo denominado de "Tupamaros" e levantam-se dúvidas sobre a destruição da residência estudantil por parte dos militares, centro de resistência e apelidada pelos estudantes de "Hospício". Temos também nesse período um forte movimento grevista que paralisou a escola por alguns meses e a presença de policiais acampados no campus. O jornal $A$ Tarde publicou uma foto em 22 de novembro de 1977, registrando a ação 
repressiva, acompanhada do seguinte comentário: "Invasão do campus por policiais - Os estudantes acompanharam calmos e curiosos a movimentação da força da PM. Para eles, uma lição visual diferente.”

Após este contexto mais geral sobre o movimento estudantil da antiga EAB, talvez nem tão ativo e combativo quanto o da cidade de Salvador, mas hoje relegado ao esquecimento, apresentamos a trajetória de Eudaldo como parte da história do movimento estudantil no Brasil, formada em sua maioria por jovens oriundos das classes médias. Ele viveu a experiência da clandestinidade, da prisão, da tortura e do exílio, sempre generoso e sensível aos problemas sociais, e abraçou de imediato determinados projetos de revolução que visavam derrubar a ditadura. Como já foi dito, nasceu em Salvador e foi um entre os vários filhos de uma família marcada pela pobreza. Para muitos dos seus companheiros ele já veio de Salvador para cursar engenharia agronômica na $E A B$ com uma sensibilidade particular para questões sociais e políticas. Muito simpático e simples, tocava violão e jogava futebol. Era bastante popular na cidade, frequentava festas e tinha boas relações com os moradores.

Tais registros que caracterizam seu jeito leve, amigo e solidário estão presentes no livro de atas do Dala, 1962 a 1968, e nos ofícios, telegramas, correspondências, poemas, textos, programa de teatro que abrangem o período de 1963 a 1978. Alguns desses documentos foram assinados por Eudaldo e endereçados à direção da escola. O conteúdo remete ao cotidiano dos estudantes e dificuldades com bolsas de estudos, problemas relacionados à reprovação de alunos, falta de livros na biblioteca, pois grande parte da verba do diretório era consumida com apostilas. Para exemplificar esse apoio às demandas internas dos estudantes pobres, Eudaldo solicita à secretaria da escola que Raymundo Santos Barros fosse incluído entre os estagiários universitários, conforme ofício datado de 27 de maio de 1968.

Preocupações com a dinâmica externa dos cursos de agronomia no Nordeste mobilizaram ações estudantis, revelando sensibilidades com relação à situação precária da Escola Agronômica Médio São Francisco. Em comunicação oficial à direção da escola, Eudaldo indica a necessidade de uma visita dos alunos da EAB a esta escola. De fato, bem antes do Golpe de 1964, a $\mathrm{EAB}$ começou a liderar um movimento pró-melhoramento do ensino agronômico da Bahia e do Brasil. Contudo, no final da década de 1960 notamos um recuo nesta posição quando ocorre o abandono da Escola Agronômica do Médio São Francisco. Vejamos a matéria publicada no Jornal da Bahia de 15 de agosto de 1966, intitulada "Estudantes de agronomia lutam: melhorar 
escolas existentes, não vir nova”. A matéria refere-se à discussão sobre a necessidade dos estudantes de que o governo estadual concentrasse esforços em uma única escola, no caso a EAB. Começa uma luta pela federalização da escola, concretizada durante o governo Castelo Branco, em 1967 e, desse modo, a proposta de incorporação da Escola Agronômica do Médio São Francisco, que vivia numa grande precariedade, foi deixada de lado.

Além dos ofícios, existe uma a prestação de contas da festa de calouros em 1968, assinada por Eudaldo, e um telegrama enviado ao senhor ministro da Agricultura em protesto ao corte de verba destinada à escola no valor de \$20.000,00 cruzeiros proveniente do Acordo Lei 2044, de 23 de outubro de 1953. O diretório solicita também a liberação de verbas existente no Fundo Federal Agropecuário para melhorar o ensino agronômico superior brasileiro.

Eudaldo, membro do DCE, redigia junto com outros colegas o Boletim do DCEAB, Diretório Central dos Estudantes de Agronomia do Brasil. Em uma de suas edições, em 1967, os estudantes denunciam o acordo MEC-USAID e proclamam que os alunos deviam estar preparados para a discussão da reforma universitária proposta pelo governo. Em outro comunicado, datado de 17 de maio de 1968, encontramos indícios da posse da nova direção do Dala, tendo como presidente Eudaldo, além do segundo secretário Joselito Matos Vieira, secretário de Intercâmbio e Cultura Abdon Jordão Filho, secretário de Imprensa e Propaganda Moacir Omena de Oliveira e Irene Ramos assumindo a Secretaria Feminina.

No livro de atas da congregação da EAB/UFBA, 1964-1972, precisamente na ata da $5^{\text {a }}$ sessão, em 7 de agosto de 1968, consta referências à atuação de Eudaldo como presidente do Dala, preocupado com as consequências da greve nacional contra a Lei Suplicy, vivenciada também pelos estudantes da EAB:

[...] sob a presidência do professor Zinaldo Figueirôa de Sena, diretor da Escola, [...] professores e os representantes do corpo discente Eudaldo Gomes da Silva e Eduardo José Nascimento. [...] O estudante Eudaldo procurou saber da presidência, se em virtude da greve que motivou o não funcionamento das aulas, se o curso seria prorrogado para atender a exigência curricular dos 180 dias. $O$ senhor presidente respondeu que iria se entender com o Magnífico Reitor, que as providências sobre a matéria tomará de um modo geral a Universidade. O professor Geraldo Pinto disse 
que as provas de junho, na sua cadeira, não foram totalmente realizadas, em conseqüência da greve estudantil, sendo interessante que o calendário para as provas restantes, seja organizado de modo a não haver acúmulo.

As pequenas iniciativas e discussões sobre os recursos destinados à educação demonstram que o movimento estudantil não se preocupava apenas com questões de natureza política, mas tinha uma inserção muito grande no cotidiano escolar, estabelecia ações para garantir a sobrevivência de estudantes sem recursos financeiros e administrava as relações cordiais ou conflituosas entre professores e alunos e a comunidade em geral. A luta pela melhoria da qualidade do ensino passava necessariamente por uma crítica à proposta de reforma universitária do governo federal. Nesse particular, Eudaldo, junto com seus colegas Abdon Jordão Filho, Igor Coelho, Armando Rosa, entre outros, exercia uma liderança genuína com maestria e sensibilidade. No gesto simbólico de ruptura com "objetivos menores" frente à tarefa de "fazer a revolução", Eudaldo desistiu de receber o diploma universitário faltando apenas 15 dias para se formar e partiu para a luta armada. Podemos afirmar que vários jovens dessa geração viveram o ápice do romantismo revolucionário, isto é, a utopia de que outro mundo era possível através do emprego das estratégias de guerrilha urbana e rural.

\section{O estudante que se fez guerrilheiro}

No sentido de desconstruir a versão oficial produzida no interior dos órgãos repressivos sobre a militância de Eudaldo e seus companheiros, coletamos depoimentos dos antigos estudantes da EAB que conviveram com ele. O objetivo consiste em inserir a sua história no quadro de uma memória social mais ampla de luta de resistência à ditadura. Ainda, como participante de organizações que defenderam projetos distintos de revolução, buscando alternativas ao regime implantado em 1964. Nos limites deste texto, analisamos os depoimentos fornecidos pelos engenheiros agrônomos Abdon Jordão Filho, Armando Rosa, Igor Coelho, Cyro Mascarenhas Rodrigues e Amilcar Baiardi entre os anos de 2008 a 2009 para o projeto de pesquisa "História e Memória do Movimento Estudantil no Recôncavo Baiano”.

Organizamos as reminiscências de acordo com os fatos e situações destacadas como as mais importantes pelos próprios depoentes. O estudo 
revelou a formação do estudante, o seu interesse pela política, ingressando posteriormente em organizações da esquerda armada que alcançaram projeção nacional no confronto com os governos militares. Com isso, ao narrar fragmentos de sua história através das lembranças dos envolvidos, estamos dando voz aos vários outros sujeitos imersos nesse cenário de lutas de resistência à ditadura na Bahia.

$\mathrm{O}$ engenheiro agrônomo Abdon Jordão Filho exerceu uma grande influência sobre Eudaldo e demais estudantes da EAB. No seu modesto depoimento, negou ser uma liderança nesse contexto, fato não confirmado pelos outros quatro depoentes. Natural de Pernambuco, Abdon participou do movimento estudantil secundarista como presidente de grêmios estudantis. Em 1961, na cidade de Caruaru, foi eleito para presidente da União dos Estudantes Secundários de Caruaru (Uesc). Ainda jovem migrou para Recife, engajando-se na campanha de governo de Miguel Arraes, em 1962. Participou do Movimento de Cultura Popular do Nordeste, viu de perto a aplicação do método Paulo Freire e manteve ligaçóes com as Ligas Camponesas, lideradas por Francisco Julião. Fez parte da equipe de 20 jovens que atuaram junto à Secretaria Extraordinária para assuntos relacionados ao problema da terra, criada pelo governo Arraes. De acordo com Abdon, a base de sustentação política dessa secretaria origina-se no Partidão, PCB, com o respaldo nas bases dos sindicatos dos trabalhadores rurais. Nessa efervescência política, conviveu com Gregório Bezerra:

Gregório Bezerra era um líder que tinha uma história bonita em Pernambuco, de resistência desde 1935, e isso fazia um pouco do imaginário da juventude e de repente conviver com uma pessoa desse padrão de cidadania, de coerência, de humildade, era quase conversar com um santo.

Quando reporta ao passado, a imagem do primeiro dia do golpe em Recife salta de sua memória: "Então eu estava no Palácio no dia 31 de março, onde saí em torno das 23 horas, não dialogando com o governador, mas presenciando toda aquela movimentação [...] temos como resistir, vamos garantir." No dia seguinte, Abdon participou de uma manifestação estudantil em defesa do governo Arraes, tendo como saldo dois estudantes mortos e algumas prisões: "As perseguições começaram, todas as pessoas que trabalhavam conosco foram indiciadas em inquérito e aí o Dops atrás de todas essas figuras, alguns foram presos, outros caíram lá na frente. Eu driblei um pouco e 
mais algum tempo saí, cheguei à Bahia de uma forma muito discreta." Chegou a Salvador em 1965, procurando levar uma vida clandestina em Cruz das Almas, apesar de ser indiciado em inquérito em Pernambuco, alcançando a absolvição em 1968:

Em novembro de 1965 chequei em Cruz das Almas nessa fase de clandestinidade e fui morar na chácara dois de julho e ali esperei o vestibular acontecer em fevereiro. Ainda na minha passagem em Salvador, eu conheci o Eudaldo e tive um relacionamento não só com Eudaldo, mas com toda a família, e Euldado era um aluno bom, aplicado, o Colégio Dois de Julho, jogava futebol e basquete.

Abdon dividiu um apartamento com Eudaldo no alojamento dos estudantes, localizado na sede da escola em Cruz das Almas. Nos idos de 1966, os dois colegas engajaram-se fortemente na campanha pela federalização da EAB e começou uma série de mobilizações para integração da Escola Agronômica do Médio São Francisco. A luta pela federalização refletiu um grau de politização que começou a incomodar a Igreja e o próprio Estado: "Existia posturas avançadas do ponto de vista da organização, de trazer ideias para o debate, reforma agrária, a questão da federalização, depois começamos a refletir sobre a Lei Suplicy, tinha um discurso forte contra os ianques, o antiamericanismo."

Comenta sobre a relação do movimento estudantil de Cruz das Almas com as representaçóes estudantis da capital, enfatizando o fato de que as lideranças influenciavam as discussões, bem como figuras nacionais como José Dirceu, Travassos e Wladimir Palmeira ocupavam o debate e a pauta local. Para exemplificar, afirma que a morte do estudante Edson Luís repercutiu fortemente entre os estudantes, passeatas de protesto foram organizadas pela escola e proliferaram discursos inflamados nas praças públicas de Cruz das Almas e Salvador.

A presença dele e de Eudaldo no diretório acadêmico foi passo importante para a escolha do nome do estudante Armando Rosa para compor a representação da EAB junto ao Congresso da UNE em 1968. Armando foi escolhido porque ele, Eudaldo e Nicolau Chaule foram indicados para compor a delegação baiana no Congresso Brasileiro de Estudantes de Agronomia, realizado em Pelotas, Rio Grande do Sul, naquele mesmo ano. A questão política, especialmente a discussão do Estatuto da Terra do governo Castelo 
Branco, dominou o congresso, que viveu uma atmosfera de "efervescência política às vésperas do Congresso de Ibiúna”.

Já formado e atuando como agrônomo, Abdon foi detido em Salvador em 1970 sob alegação de envolvimento com o movimento de trabalhadores rurais. Antes, porém, rememora o contexto de sua formatura e a ausência sentida do grande amigo, Eudaldo: "Foi a única formatura coletiva que aconteceu na história da Bahia, foi exatamente com o reitor Roberto Santos, no ginásio Antonio Balbino em Salvador [...] o reitor não teve condições de continuar [...] abriu a sessão e foi impedido pelas centenas de estudantes que aproveitaram para protestar [...] terminou não havendo colação de grau." As formaturas foram ressignificadas pelos estudantes que aproveitavam tais brechas para protestar contra a ditadura. Os discursos de formatura são reveladores de tal prática.

Encerra o depoimento, apresentando o perfil digno e sensível do grande amigo dos tempos de movimento estudantil em Cruz das Almas:

Eudaldo trazia da família uma dignidade muito grande, dos pais, família pobre mas muito digna, muito ativo, foi uma pessoa que eu conheci sem medo, não tinha medo do enfrentamento, não tinha medo do futebol, não tinha medo de entrar nas discussóes, não tinha medo do debate com os professores, não tinha medo de se posicionar, muito embora a sua postura na cidade nunca fosse radical, ele foi uma pessoa que conviveu com desigualdades, estudantes pobres, estudantes ricos, ele tava sempre solidário a orientar as pessoas [...] ele tinha uma formação muito boa, na matemática, nas ciências, nas químicas, um relacionamento com alguns professores [...] talvez ele estivesse no patamar de compreender todas aquelas fragilidades que nós viviamos, digo o embate entre estudantes forasteiros e estudantes nativos [...] uma rivalidade muito forte... então o papel sutil de Eudaldo, as articulações com as famílias da cidade, com os colegas no campo de futebol, nas festas, especialmente de São João, facilitou muito e quebrou muito dessas arestas entre os estudantes. (Grifo nosso).

Outro entrevistado, o engenheiro agrônomo e professor Armando Rosa nos forneceu mais um depoimento significativo para recompormos a vida de Eudaldo. Ele nunca exerceu a profissão, dedicando-se ao ensino de química, primeiramente na EAB, depois em colégios e cursinhos pré-vestibulares em Salvador. Nos anos 1960, junto com Eudaldo e Abdon, participou da direção 
do Dala. Nessa condição, representou a escola como delegada da Bahia no Congresso de Ibiúna em São Paulo, 1968. Conta as peripécias para se chegar a São Paulo no esquema de segurança montado pela direção da UNE e as duras acomodações durante a permanência dos estudantes em Ibiúna. A chegada dos policiais, o cerco repressivo e a ida em caminhóes alternados para a capital paulistana, o alojamento no Presídio Tiradentes são destacados por ele como acontecimentos traumáticos: "Não nos bateram, não fizeram tortura física nenhuma, mas muita tortura psicológica, a comida era uma lavagem de porco [...] ficamos traumatizados e à noite não deixavam a gente dormir direito [...]. O governador paulista Laudo Nautel doou cobertores que até hoje guardo de lembrança." Após 12 dias de cárcere, os estudantes foram enviados de volta aos seus estados de origem. Comenta o tom festivo da volta, uma viagem bastante descontraída, mas os policiais queriam deixá-los em Feira de Santana, receando manifestações estudantis na capital. Eles não aceitaram, chegaram à capital e permaneceram ainda mais cinco ou seis dias presos em Salvador até a liberação definitiva. Armando, durante a entrevista, nos mostrou a revista Veja de 16 de outubro de 1968 - Todos presos. Assim acabou o Congresso da ex-UNE, apontando para o seu rosto estampado na foto de capa.

O AI-5 e a repressão que se seguiu atingiram a sua vida escolar. Armado Rosa foi expulso da EAB, ficou sem direito a trabalho como professor do Colégio Alberto Torres, localizado próximo à escola: "A prisão custou muito caro, mas não tenho nenhum arrependimento, se tivesse outro Congresso da UNE com os mesmos riscos eu acho que eu correria hoje, com 63 anos [...] então, veio o AI-5; quando fui me matricular, o Alino me disse o senhor vai ser cassado viu." Armando viveu com muitas dificuldades, seu pai faleceu nesse mesmo ano e ele necessitava rapidamente de um emprego. Depois da prisão, além de ser estudante, era cassado, portanto, ninguém confiava no seu trabalho. Com muito esforço foi acolhido por um professor em Jaguaquara: "Jaguaquara foi como se fosse um exílio, de vez em quando o Eudaldo mandava lá um agente. Inicialmente pensei que fosse um agente do Dops, mas depois ele disse que era de Jequié e estava ali para organizar uma célula." Armando informou que ia se casar e o tal agente respondeu: "O nosso Che Guevara dizia que o casamento é o túmulo do revolucionário.”

Foram três anos e meio para que Armando pudesse regressar à escola e concluir o curso de agronomia. Nesse intervalo passou a se interessar por química analítica e tornou-se professor da EAB após a sua formatura. Para ele, 
Eudaldo não tinha um perfil de liderança entre os estudantes, de fato quem a exercia era o Abdon, estudante mais experiente e amigo de Eudaldo:

Quando entrei na Escola de Agronomia eu tive a sorte de conviver com pessoas que tinham realmente uma formação política que contaminou. Tínhamos com Eudaldo muitos momentos de reflexão, de estudo, doutrinação, ele mandava ler aqueles documentos, a gente discutia aquele negócio todos $[. .$.$] algumas divergências.$

Armando Rosa nos legou um postal com a foto de Che Guevara enviada para ele por Eudaldo, que escreveu a seguinte declaração: "Armando: El revolucionário verdadero está guiado por grandes sentimentos de amor. ES impossible pensar em um revolucionário auténtico sin esta qualidad - CHE - Por amor e só por amor é que lutamos pela revolução proletária." A influência da Revolução Cubana e a liderança de Che Guevara marcaram profundamente o imaginário político de jovens muitas vezes fugindo da repressão e escondidos no interior do Brasil. Esse foi o caso de Armando Rosa, um sorridente professor de química que buscou "asilo político" na cidade de Jaguaquara, interior da Bahia.

Entrevistamos também o único residente em Cruz das Almas ainda hoje, o engenheiro agrônomo aposentado Igor Coelho. Ingressou na EAB em 1967, foi membro da direção do Dala junto com Eudaldo, Abdon e Armando. No início da conversa, comunicou o desejo de escrever um livro sobre Eudaldo e tratou de definir o seu perfil: "Eudaldo já veio de Salvador com muita sensibilidade, com esse perfil, e aqui ele foi talvez um líder." Conta que era carismático e admirado até por um político de direita da cidade. Lembra do episódio do cinema durante a festa de São João. Um grupo de estudantes queria quebrar o cinema por puro vandalismo, mas Eudaldo controlou a situação e de forma equilibrada perguntou. "Qual é a consequência de quebrar o cinema? O resultado é ficar sem o cinema?” Recorda que Eudaldo nas festas do São João tomava licor na casa de políticos até da União Democrática Nacional (UDN). Alguns revelaram espanto quando se soube da sua morte: "Eudaldo? Aquele miúdo daqui? Não pode ser. Aquele miúdo não tinha representação para a dimensão da transformação que ele queria. Estava muito adiante do nosso tempo."

Lamenta que Eudaldo, morto, não se formou: "No máximo 15 dias antes da formatura, ele resolveu entrar para a clandestinidade. No dia em que 
ele foi embora para clandestinidade ele visitou a minha mãe e inventou uma mentira, disse à minha mãe que ia fazer um curso na Venezuela, minha mãe passou a vida toda acreditando nisso [...] ele era muito sensível [...] muito cativante, tocava violão, acho que escrevia." A segunda pessoa sacrificada, diz Igor, foi Armando Rosa: "Armando Rosa foi aquele que não pagou com a vida como Eudaldo, mas pagou porque foi jubilado do curso simplesmente porque estava no Congresso de Ibiúna”. Eudaldo foi para o Congresso de Agronomia no Rio Grande do Sul junto com Abdon: "Sujeito extraordinário [...] uma das lideranças da agronomia na Bahia até hoje. Eudaldo e Abdon eram as maiores lideranças, os principais intelectuais, eram os elementos mais politizados." Os livros e documentos de Eudaldo ficavam escondidos na casa do professor José Vasconcelos, amigo e muito próximo da turma:

Os livros, que se pegasse a gente com aqueles livros, não sei se vinha livro da China, quando eu via era Eudaldo com uma mala, livro de Mao Tse-tung, aqueles livros ia botar onde? Botava na casa do professor Vasconcelos. Eudaldo já até se organizava com uma coisa assim, pensando no aprofundamento da guerrilha [...] tinha um... talk-walk que chamam? Um radinho de comunicação.

De volta ao Brasil em meados de 1973, Igor conta que Eudaldo marcou um encontro entre ele e uma moça loira em Salvador, pequena, suíça ou sueca, não soube precisar, e passou a senha para que ambos se reconhecessem. O ponto tinha a finalidade de que fosse entregar uma encomenda em São Paulo. Igor cumpriu o combinado, mas passou por muitos apuros em terras paulistanas. Mesmo assim colaborou bastante nessa posição de "pombo-correio" a serviço dos companheiros.

Recorda também do papel importante de Cyro Mascarenhas Rodrigues, outro agrônomo, funcionário da Empresa Brasileira de Pesquisa Agropecuária (Emprapa) que sempre ajudava o grupo fornecendo tinta e papel para imprimir os textos, panfletos, auxiliando na confecção dos materiais distribuídos durante as manifestações em Cruz das Almas e Salvador: "Eudaldo dizia: 'Precisamos imprimir não sei o quê.' [...] Aí, o coitado do Cyro, funcionário, tinha um jeitinho de dar escondido as tintas que era para a manifestação em Salvador.”

A importância da militância de Cyro Mascarenhas Rodrigues também foi comprovada através de entrevista. Ele nos brindou com um poema em 
homenagem a Eudaldo, publicado no livro Poemas do cárcere, reunindo 15 poemas e um soneto escrito, em sua maioria, em 1964, quando o autor, com apenas 20 anos, foi preso político na Fortaleza de Monte Serrat, em Salvador. O primeiro poema, "Desperta povo", publicado pouco antes do golpe, teria sido um dos motivos da reclusão. A cópia que fora publicada em jornal local de Cruz das Almas estava no dossiê em poder dos seus inquisidores. Segundo Cyro, o cárcere improvisado era um grande barracão da oficina de material bélico do exército, naquele quartel. Fora adaptado às pressas para receber prisioneiros e as instalações eram muito precárias: "Não existiam camas, apenas colchões espalhados pelo chão, um banheiro coletivo de dimensões limitadas para servir a uma população flutuante de uns 50 homens. Mas em meio a tanta privação, um privilégio inconteste: o portão de acesso ao barracão era um gradeado de aproximadamente três metros de largura por dois de altura. A vista para o mar era impressionante, pois estávamos no alto de um monte." Em meio a tudo isso, um soneto para Eudaldo, um amigo guerrilheiro:

\section{UM SONHO}

Nossa escola... minha memória um porão... meu inconsciente Agronomia... Biblioteca, de repente entre livros e panfletos a tua boina e tua mochila.

E dentro de empoeirados escaninhos novos despojos do herói guerrilheiro calça Lee, camisa cáqui e uma bota de campanha envolta no verde de uma jaqueta do Ipanema Futebol Clube.

E atrás daquela estante cheia de livros em alemão a arma que não te deram a chance de disparar em tua defesa.

Reúno, surpreso, teus despojos penso usá-los 
e sair por aí

perpetuando a tua lembrança.

Mas como caber meu corpo franzino

na roupa que vestiu teu corpo forte?

E os meus pés frágeis

em tuas botas de andarilho?

Restam a boina, a arma e a mochila.

$\mathrm{Na}$ mochila guardarei os sonhos

alimento do meu dia a dia;

a boina até que me pega bem

porei a estrela Che.

Enquanto da arma, penso o que fazer,

ela escorrega-me das mãos

e dispara rajadas de rosas

alternadas com pão e vinho

que inundam a Biblioteca,

saindo por portas e janelas

ganhando ruas

de todas as cidades

transfigurando a nação.

Nas palavras de Cyro, "Liberdade é um lamento solene que reverencia a deusa guardiã desse direito inalienável do cidadão. Uma condição que só parece devidamente valorizada quando nos é cerceada ou nos sentimos ameaçados por sua falta." Assim finaliza sua breve entrevista, contribuindo para a construção de uma memória heroica do companheiro que ainda, segundo ele, deve receber uma justa homenagem em terras baianas, além de ser reconhecido com um mártir pela associação de engenheiros agrônomos.

Nessa mesma linha interpretativa, segue o depoimento de uma das principais lideranças do movimento estudantil em Cruz das Almas, além de ex-guerrilheiro e responsável por "cooptar", para utilizar um jargão da época, Eudaldo para a luta armada. Trata-se da entrevista realizada com o engenheiro agrônomo e professor titular aposentado da UFBA e UFRB, Amilcar Baiardi. Atuou no movimento estudantil em Cruz das Almas, como presidente do Dala em 1964. Com a instauração do golpe, liderou uma possível resistência armada no interior baiano, logo frustrada: 
Estava em Salvador no dia 31, escapei por pouco da invasão da Residência Universitária [...] organizei algumas pessoas e trouxe-as aqui para Cruz das Almas na condição de resistir [...] nós criamos um grupo de resistência [...] chegamos a reunir armas e preparar um monte de coquetel molotov porque a nossa ideia era atacar o tiro de guerra e a polícia. Nos armamos e supomos que ocorreria resistência no Brasil e na Bahia, especialmente em Feira de Santana e Vitória da Conquista, onde os prefeitos eram progressistas. Mas não aconteceu nada disso.

Como líder estudantil é sempre referenciado pelos compa nheiros da geração de Eudaldo. Armando Rosa, Abdon Jordão Filho e Igor Coelho admiram sua capacidade de inteligência e coragem, formulando uma percepção do herói destemido. Amilcar orgulha-se de que convenceu Eudaldo da necessidade das ações armadas no enfrentamento com a repressão. Em suma, prevalece uma memória mítica sobre a passagem de Amilcar pela $\mathrm{EAB}$, à qual podemos acrescentar que ele próprio constrói uma leitura da sua história, dando-lhe o estatuto de agente memorável no campo da resistência revolucionária. Durante a entrevista nos entregou uma documentação arquivada pelo Dops/RJ, onde encontramos dados de sua ficha criminal:

Usa o codinome de "MARCOS" e pertence à Organização clandestina revolucionária de cunho marxista-leninista, denominada OPM, cujos objetivos são a implantação da guerrilha e da luta armada no país, derrubada do governo e implantação do regime socialista de fundo marxista-leninista. Recebia dinheiro da Organização como militante da mesma: comprou um carro de marca Volkswagen para ser empregado nas atividades ilícitas da Organização com dinheiro da mesma. É Componente do subsetor de treinamento de guerrilhas. Foi Presidente do Diretório Acadêmico Landulfo Alves, da Escola de Agronomia da Bahia. Foi um dos organizadores das Ligas Camponesas de Cruz das Almas e Simões Filho (Água Cumprida) na Bahia, sendo igualmente notória a sua vinculação ao sindicato dos trabalhadores na indústria fumageira de Cruz das Almas e constatada atividade subversiva. Figura numa relação de militantes aliados e simpatizantes da extinta COLINA, da VPR e da VAR-PALMARES. (Ofício n ${ }^{\circ} 52$, 15/10/1970. Subdivisões de Informações - Dops).

Amilcar arregimentou Eudaldo para a guerrilha durante um breve período em que ministrou um curso na EAB. Conquistou a confiança do 
estudante e colocou-o em contato com as organizações armadas Comandos de Libertação Nacional (Colina) e VPR, portanto, considera-se responsável por esse ritual de passagem. Ao falar sobre Eudaldo no presente em que pratica o exercício rememorativo, já compreende o sentido político do personagem que pretende homenagear, transformando-o em um símbolo de resistência à ditadura na Bahia:

Eudaldo está para a categoria de agrônomos assim como Wladimir Herzog está para a de jornalistas, Jorge Leal, para a de engenheiros civis, Monteiro, para a de geólogos, Carlos Alberto Freitas, para a de sociólogos e assim por diante. Relembrá-lo, homenageá-lo é um esforço para evitar que o tempo encubra os crimes da ditadura e uma decisão de inseri-lo entre aqueles que merecem o nosso eterno culto.

Para Amilcar, a prática política de Eudaldo transcendia as lutas estudantis na medida em que participava e apoiava, sempre que possível, as lutas dos trabalhadores rurais da $\mathrm{EAB}$ e dos trabalhadores de outras categorias do município, como, por exemplo, os da indústria fumageira. Explica a passagem de Euldado do movimento estudantil para a luta armada da seguinte maneira:

Ao se aproximar o fim do ano de 1969, quando deveria concluir o curso de agronomia, Eudaldo passou a viver o seguinte dilema: concluir a graduação correspondendo às expectativas dos pais passando a ajudá-los na educação dos irmãos mais jovens ou dedicar-se integralmente à resistência armada com todas as implicações do momento, quais sejam: a clandestinidade e risco de vida. A consciência de que o mais justo seria lutar pelo fim da opressão e do horror que se expressavam pela repressão violenta a todo tipo de oposição autêntica e pelo arrocho salarial pesou nesta difícil decisão e Eudaldo pôs de lado, definitivamente, a possibilidade de encaminhar soluções individuais.

Em Carta dirigida aos colegas de turma em dezembro de 1969 ele justificava o seu gesto de não "colar grau", afirmando que seu compromisso maior era com a luta contra a ditadura e que ser ou não ser engenheiro agrônomo deixara de ter importância fundamental em sua vida. 
Outro depoimento heroico sobre Eudaldo foi dado por José Rodrigues Filho em janeiro de 1983 ao amigo Amilcar Baiardi, que nos ofereceu uma cópia do manuscrito:

Eu vi o homem herói no restaurante Universitário, em período de exceção dando exemplo de honradez aos companheiros, almejando um bom futuro para a Nação. Um grito de amor ao homem e a terra. Do peito do herói emanava. Ouvi seu grito de avante contra a guerra. Grito de união que a pátria suscitava. Ordeiro, nos gestos que dignificam o ser humano. Modesto, no trato com os demais. Ergueu seu punho contra o controle dos tiranos. Dez anos após as reminiscências, ardem no meu cérebro com reflexões, sugerindo o embate fora das ciências, imolando a vida no mar de paixões... liberdade!... liberdade!... liberdade! Vai clamando o homem herói já imortal. Ainda não morreu eis a verdade.

No artigo publicado no jornal $A$ Tarde, datado de novembro de 1999, intitulado "Lembranças do mar cinzento $(\mathrm{X})$ ", o jornalista Emiliano José ao sintetizar o seu livro de memórias, Galeria $F$, refere-se ao contexto de treinamento militar de guerrilha na Bahia. Relata a trajetória militante de Ruy Patterson, mas cita como parte do mesmo grupo Eudaldo e Amilcar:

Ia para o campo, nas proximidades de Salvador. Às vezes, Camaçari, outras vezes Mata de São João. Entrava na mata, aprendia a lidar com armas e a fazer explosivos. Com ele, Nemésio, Getúlio, Eudaldo Gomes, entre outros. Os melhores professores de explosivos, segundo o que conta Rui, foram Amilcar Baiardi e Flávio Tavares. Esse treinamento desenvolveu-se até o primeiro semestre de 1969. (Grifo nosso).

Para finalizar a discussão das memórias "vivas" sobre Eudaldo, podemos afirmar que nas narrativas de Abdon Jordão Filho, Armando Rosa e Igor Coelho o tempo vivido na universidade ganha centralidade. Momento em que o afeto, o lúdico, a luta cotidiana por mais verbas, as preocupações com o ensino de agronomia misturam-se com a dimensão política do personagem. A recusa da formatura é sentida por todos os companheiros. Tais narrativas disseram muito com relação ao Eudaldo estudante, não ocorrendo o mesmo quando buscamos compreender o Eudaldo guerrilheiro. Poucos falaram sobre o assunto, prevalecendo o silêncio, certo incômodo ou desconhecimento dos 
fatos ocorridos com ele após a sua saída de Cruz das Almas em finais de 1969. Assim, inferimos que o Eudaldo, estudante, é celebrado e reconhecido, mas o guerrilheiro é de difícil compreensão para aqueles que hoje já estabeleceram ou foram influenciados por uma determinada leitura presente na mídia e nos demais escritos memorialísticos de crítica a experiência da luta armada ou de enquadramento dessa memória como "aventura juvenil". Vale lembrar que existe um empenho, especialmente nas falas e escritos aqui analisados, de promover na Bahia uma heroificação do nosso personagem.

\section{Eudaldo, luta armada e repressão}

Encontramos uma literatura que apresenta Eudaldo como símbolo do movimento de resistência à ditadura civil-militar no Brasil. No livro de Gilney Viana (1996) Massacre da Chácara São Bento. (Mortos e desaparecidos II), o autor faz uma breve homenagem às vítimas do episódio conhecido como "Massacre da Chácara São Bento". Traz uma pequena biografia de Eudaldo Gomes da Silva, Soledad Barret Viedma, Evaldo Luiz Ferreira de Souza, Pauline Reichstul, José Manuel da Silva e Jarbas Pereira Marques, vítimas do referido episódio. Outro livro mais denso e importante, organizado por Nilmário Miranda e Carlos Tibúrcio (2008), intitulado Dos filhos deste solo. Mortos e desaparecidos politicos durante a ditadura militar: a responsabilidade do Estado, foi publicado pela Fundação Perseu Abramo em 2008. No livro, encontramos a reconstituição das diversas versões elaboradas pela polícia política liderada pelo Delegado Sérgio Paranhos Fleury para encobrir a "verdade".

Aqui, sistematizamos algumas informações presentes em jornais e na documentação coletada no Departamento Estadual de Ordem Política e Social (Deops) de São Paulo referente ao militante político Eudaldo. Não podemos esquecer que a VPR foi uma das organizações que mais se destacou na luta armada contra a ditadura militar, abrigou em seu seio duas personalidades que jamais serão esquecidas na história do Brasil. Uma, por sua bravura, por ter deixado uma promissora carreira militar para se entregar à luta pela democracia e pelo socialismo, o capitão Carlos Lamarca. Outra, por ter traído essa luta da forma mais vil que se pode conceber, entregando dezenas, talvez centenas de companheiros à sanha de repressão, entre estes, difícil de acreditar em tamanha sordidez, a própria mulher grávida: trata-se de José Anselmo dos Santos, o tristemente famoso ex-cabo Anselmo. 
Através das manchetes dos jornais publicadas no dia 11 de janeiro de 1973, podemos perceber a construção de versões sobre o episódio do Massacre da Chácara São Bento. Vejamos algumas delas: "Segurança acaba com terror no Grande Recife" (Diário de Pernambuco); "6 terroristas mortos em Paulista" (Jornal do Commercio); "Desarticulado um reduto terrorista em Pernambuco" (Folha de S. Paulo). O Jornal Hoje, da região metropolitana do Recife, divulgou a nota oficial dos órgãos de segurança, segundo a qual a polícia teria descoberto que um grupo da VPR estaria realizando um congresso na chácara São Bento, localizada no município de Paulista. Chegando ao local, os policiais deram voz de prisão aos militantes, que reagiram, travando-se uma troca de tiros. No final, cinco participantes da reunião haviam morrido e um sexto escapara, mas foi localizado no dia seguinte em Olinda, resistiu à prisão e também foi morto.

Essa falsa versão de tiroteio e morte na própria chácara já foi confrontada com depoimentos de várias testemunhas. No apreço à verdade, levados para o quartel do IV Exército em Recife, foram torturados até a morte. Segundo o depoimento de Amilcar Baiardi: "Durante o trajeto usaram uma caminhonete do Incra, o que revela anuência do delegado regional na época, indicado pelo senhor Moura Cavalcanti. Levados para o QG do IV Exército em Recife foram todos torturados e mortos, sem que às famílias fossem entregues os corpos, face às violências cometidas."

Os nomes dos mortos são destacados. O Jornal do Commercio editado no Recife em 11 de janeiro de 1973 apresenta uma breve biografia de Pauline Reichstul. Diz que ela participou de um curso de guerrilha em Cuba, integrante da Vanguarda Popular Revolucionária e da Amnesty International, "banida" do Brasil com o seu companheiro Eudaldo Gomes da Silva. Outro artigo do mesmo jornal, datado de 11 de janeiro de 1973, sob o título "Desbaratado Congresso do Terror Paulista", refere-se às circunstâncias em que se deram a morte de Eudaldo e dos outros participantes, considerando todos "terroristas" da VPR.

Nos acervos do Deops/SP, consta um relatório do Serviço de Informaçóes de 2 de maio de 1973 que apresenta um artigo publicado no n. 5 do jornal Campanha, publicado em Santiago do Chile pela VPR, em protesto pela morte dos seis integrantes da organização. $\mathrm{O}$ artigo também acusa José Anselmo dos Santos, o ex-cabo Anselmo, de traição. Outro relatório da Divisão de Informações do Deops/SP, de 17 de julho de 1978, informa que Eudaldo foi "banido", preso em 1970, membro da VPR da Guanabara e da 
VAR-Palmares. O seu nome consta na relação de pessoas expulsas do território nacional em troca do embaixador da Alemanha Ocidental, sequestrado em 11 de junho de 1970.

Ainda, em termos de documentos produzidos pela repressão policial, encontramos um relatório da Delegacia de Segurança Social de Recife à Auditoria da $7^{\text {a }}$ CJM, de 24 de abril de 1973, que informa sobre as circunstâncias em que se deram a morte dos militantes, bem como a localização de outros "aparelhos" dessa organização. Destaca algumas informações prestadas por Jorge Barret Viedma, irmão de Soledad, e alerta sobre "o quão é perigosa a organização citada”. Além deste, mais um relatório, apreendido pelo Dops, denunciando mortes de presos políticos aos bispos do Brasil, enumera os nomes dos militantes mortos da VPR. O documento foi elaborado pelo Comitê de Solidariedade aos Presos Políticos do Brasil em fevereiro de 1973.

Novas versões surgiram por parte dos militantes e parentes que viveram a época, elucidando o caráter bárbaro da aplicação das torturas que os levaram a morte. Depoimentos concedidos à Comissão Nacional de Mortos e Desaparecidos e ao Comitê Brasileiro pela Anistia por pessoas que presenciaram a prisão são reveladores da submissão dos seus corpos à prisão e a tortura. Amilcar assevera que um ano e meio depois esteve no mesmo cárcere que Eudaldo em Recife e recolheu o seguinte depoimento de um dos seus carcereiros: "Portou-se como um revolucionário, em nenhum momento pediu clemência, nem deixou de afrontar os seus algozes, passando-lhes na cara o papel que estavam representando."

\section{Palavras finais}

Ultrapassando uma mera busca de sentindo para o passado, a pesquisa contribui para uma reflexão sobre o presente, denunciando mais uma vez os crimes cometidos pela comunidade de segurança e informação e indagando sobre os acervos da repressão que, no caso específico do estado da Bahia, pouco ou nada se conhece do seu destino. No confronto, a memória estudantil do Recôncavo da Bahia evidencia o grau de resistência daqueles que ousaram lutar e desafiar o poder instituído.

Nas cidades do interior do país as notícias e os impactos da ideologia e das políticas dos governos militares, aparentemente, não foram tão visíveis nem tão intensos. No entanto, o estudo aqui empreendido demonstrou que 
recuperar particularidades locais amplia, corrige e reconstrói interpretações cristalizadas por certa historiografia do movimento estudantil muito centrada nos estudos dos grandes centros urbanos. Além disso, permite questionar uma memória instituída pela própria UNE, quando elege quais os sujeitos a serem lembrados e os relegados ao esquecimento. No caso específico de Eudaldo Gomes da Silva, não foi a nossa intenção realizar um trabalho biográfico, mas recuperar alguns fragmentos de sua trajetória que não é só sua, mas que revela a experiência de tantos outros que respiraram o oxigênio de uma época em que a "aventura" do fazer coletivo anunciava projetos de mudar o mundo.

\section{Referências}

BAIARDI, A. O papel do Imperial Instituto Bahiano de Agricultura na formação da comunidade de ciências agrárias do Brasil. In: CONGRESSO LUSO-BRASILEIRO DE HISTÓRIA DA CIÊNCIA E DA TÉCNICA, 1., 2000, Évora. Actas... Évora: Editora da Universidade de Évora, 2000. p. 453-465.

MIRANDA, N.; TIBÚRCIO, C. (Org.). Dos filhos deste solo: mortos e desaparecidos políticos durante a ditadura militar: a responsabilidade do Estado. São Paulo: Fundação Perseu Abramo, 2008.

VIANA, G. Massacre da Chácara São Bento. (Mortos e desaparecidos II). Brasília, 1996.

Resumo: O texto busca recuperar a história singular do estudante Eudaldo Gomes da Silva, presidente do Diretório Acadêmico Landulfo Alves (Dala), em 1968, pertencente à antiga Escola Agronômica da Bahia, EAB, hoje conhecida como UFRB. Além de líder estudantil, Eudaldo foi militante da VPR, Vanguarda Popular Revolucionária, banido do Brasil em 15 de junho de 1970, por ocasião do sequestro do embaixador da Alemanha, Von Holleben, com mais 39 presos políticos. Retornando ao Brasil clandestinamente, foi morto no dia 7 de janeiro de 1973, juntamente com outros militantes, no município de Paulista, Pernambuco. O caso é conhecido como "Massacre da Chácara São Bento". Traídos pelo ex-cabo Anselmo, todos foram presos pela equipe do delegado Sérgio Paranhos Fleury, que os torturou até a morte. A intenção da pesquisa é mapear alguns interlocutores ainda vivos que militaram no movimento estudantil junto com Eudaldo e que até hoje conservam suas lembranças. Para tal fim, inserimos a sua história no contexto do movimento estudantil do Recôncavo Baiano, especialmente as contestações na conjuntura do pré-golpe de 1964, no ano emblemático de 1968 e no processo de reorganização estudantil em meados dos anos 70.

Palavras-chaves: movimento estudantil, luta armada, Recôncavo Baiano. 
Between the school movement and the armed struggle: Eudaldo Gomes da Silva and the Massacre of São Bento Ranch

\begin{abstract}
The text aims to recuperate the singular story of the student Eudaldo Gomes da Silva, President of the Landulfo Alves Directory of Agronomy (Dala), in 1968, which belonged to the ancient School of Agronomy of Bahia, EAB, today known as UFRB. Besides being a school leader, Eudaldo was militant of the VPR, Revolutionary Popular Vanguard, banned from Brazil on June, 15th, 1970, because of the kidnap of the Germany Ambassador, Von Holleben, with more 39 political arrested. Returning to Brazil as a clandestine, he was killed on January, 7 th, 1973, together with other militants, in the city of Paulista, Pernambuco. The case is known as the "Massacre da Chácara São Bento". Betrayed by Corporal Anselmo, all of them were arrested by the team of Marshal Sérgio Paranhos Fleury, who tortured them until death. The intention of the research is mapping the many interlocutors still alive that militated in the school movement with Eudaldo and still today keep their remembrances. To this objective, we inserted his story in the school movement of Recôncavo Baiano context, specially the contestations in the conjuncture of the pre-strike of 1964, in the emblematic year of 1968 and in the school reorganization process in the early 70 's.
\end{abstract}

Keywords: school movement, armed fight, Recôncavo Baiano.

Recebido em 01/10/2012

Aprovado em 19/11/2012 